\title{
Status of Heart Failure During COVID-19 Lockdown: A Multi-centric Study From Southern India
}

\section{Ramachandran Meenakshisundaram ( $\nabla$ rmsundarchandran@gmail.com )}

Manian Medical Centre, Power House Road, Erode, Tamil Nadu 638001, India https://orcid.org/00000002-1281-3346

\section{Subramanian Senthilkumaran}

Manian Medical Centre, Power House Road, Erode, Tamil Nadu 638001, India

\section{Ponniah Thirumalaikolundusubramanian}

Trichy SRM Medical College Hospital and Research Centre, Irungalur, Tiruchirappalli, Tamil Nadu 621105, India (affiliated to The Tamil Nadu Dr.M.G.R. Medical University, Chennai)

\section{Melvin Joy}

Meenakshi Mission Hospital and Research Centre, Madurai, Tamil Nadu 625107, India

\section{Narendra Nath Jena}

Apollo Specialty Hospitals, Tiruchirappalli, Tamil Nadu 620 010, India

\section{Shyamsundar Ayyasamy}

Sri Gokulam Specialty Hospitals, Salem, Tamil Nadu 636004, India

\section{VP Chandrasekaran}

Sri Gokulam Specialty Hospitals, Salem, Tamil Nadu 636004, India

\section{Research article}

Keywords: COVID-19, Heart failure, public education, preventive methods, Virtual clinic, lockdown

Posted Date: August 6th, 2020

DOI: https://doi.org/10.21203/rs.3.rs-41695/v1

License: (c) (i) This work is licensed under a Creative Commons Attribution 4.0 International License. Read Full License 


\section{Abstract}

\section{Background:}

Severe acute respiratory distress syndrome coronavirus (SARS CoV2) infection (COVID-19) has affected many countries globally. During COVID-19 lockdown, there has been a reduction in emergency room presentations and subsequent hospital admissions for many diseases.

\section{Objective:}

Our aim was to find out the statusof heart failure (HF) cases treated in the hospitals of during COVID-19 lockdown period, and to compare these with those cases treated during no-lockdown period and highlight the possible reasons for variations.

\section{Methods:}

A retrospective observational study was carried out across the nine-private hospitals located in four different cities of Tamil Nadu state, Southern India. Data on HF and emergency room attendance were collected for lockdown period (April 2020) and no-lockdown period (February 2020 as well as April 2019 and 2018) and analysed statistically.

\section{Results:}

During the lockdown period, there were 30 to $33 \%$ reductions in the emergency room attendance, whereas the total HF cases were more than no-lockdown period. Among HF, the proportion of ischemic HF was decreased, but the proportion of non-ischemic HF was increased, and these were independent of gender and ejection fraction sub-category.

\section{Discussion:}

Our observations of reduction in ischemic HF was attributable to steep reduction in air quality index in these cities, and a rise in non-ischemic HF could be due to doctor centred practice, lack of doctor-patient communication, under-utilisation of healthcare technologies including telehealth services, and poor compliance resulting in acute decompensation.

\section{Advance In Knowledge:}

1. Attenuation of ischemic HF is due to steep reduction in air pollution index.

2. An upsurge in non-ischemic HF is attributable to doctor centered practice, lack of doctor-patient communication, under-utilisation of healthcare technologies including telehealth services, poor compliance, and underinvestment in public health system and social health.

3. Government may consider a policy to promote telehealth and virtual consultation services and educating the public and patients to utilize such technologies for the essential healthcare needs and 
also, policy makers may consider an upgrade in social benefits to provide essential health devices for the needy.

\section{Background:}

Infection due to Severe acute respiratory distress syndrome coronavirus 2019 (SARS CoV2, COVID-19) has become a pandemic and made an impact on all spheres of life. Government of India has implemented a strict COVID-19 lockdown from March 25, 2020(1). Current medical literature has shown a reduction in the emergency room presentations of medical admissions secondary to myocardial infarction (MI), heart failure (HF), stroke etc., during COVID-19 lockdown period worldwide(2-5). Hence, the present study was performed to find out the status of heart failure (HF) cases treated in the hospitals during lockdown period, and to compare these with those cases treated during no-lockdown period and highlight the possible reasons for variations.

\section{Methods:}

A multi-centric retrospective observational study was undertaken across nine-private hospitals, that follow similar methods for data collection and adhere to the evidence-based guidelines for management of HF. These hospitals are located in Madurai, Thiruchirapalli, Erode and Salem in the state of Tamil Nadu, Southern India. All these cities are located within 125 miles radius with similar socio-demographic and cultural background. The data on age and gender for HF cases were collected for lockdown (April 2020) and no-lockdown periods (February 2020, April 2019 and 2018). Total number of emergency room (ER) presentations were also collected. HF cases were categorized on the basis of ejection fraction (EF) (6) as those with preserved EF, EF $\geq 50 \%$ (HFpEF) and reduced EF, EF $<40 \%$ (HFrEF). Since the numbers of $\mathrm{HF}$ cases with mid-range EF (EF 40-49\%) were small, it was included in HFrEF. Also, HF cases were further sub-classified as ischemic HF (IHF) and non-ischemic HF (NIHF). The proportion of cases treated during lockdown and no-lock down periods were compared for each parameter. The p-value and 95\% confidence interval for the proportion difference were calculated and analysed using $\mathrm{R}$ software version 4.0.0. Data for March 2020 was not considered, since it was a mixture of lockdown and no-lockdown.

\section{Results:}

The overall mean age of patients treated for HF during the lockdown and no-lockdown periods were 49 and 56 years respectively and it was independent of the category and underlying aetiology. The details of HF and ER admissions are given in Table I and the statistical analysis for these data are furnished in Table II, respectively. There were 30 to $33 \%$ reductions in the ER attendance during lockdown. On the contrary, the total HF cases treated were more during lockdown on comparison with no-lockdown periods and was statistically significant $(P<0.001)$. On the other hand, during lockdown the proportions of IHF were decreased, whereas NIHF were increased, when compared with no-lockdown periods and the difference was statistically significant for February 2020 and April 2018, but not for April 2019. There was 
no statistical significance noticed for the category of HF when analysed for EF and gender, and the details are provided in the Table II.

\section{Discussion:}

Worldwide, COVID-19 pandemic has caused tremendous burden on healthcare, even though there is a reduction in the number of ER attendance(2). During the lockdown period, HF constituted $25 \%$ of our ER cases, whereas it was around $13 \%$ during no-lockdown periods, which was in contrary to the published reports(3-5). However, a reduction in the proportion of IHF cases was observed which was likely secondary to reduction of acute MI during COVID-19 lockdown(7) and was also attributable to steep reduction in air quality index in these cities (https://tnpcb.gov.in/air-quality.php), whereas the proportion of NIHF have increased during lockdown, when compared with no-lockdown period. Air pollution and extreme weather conditions have been shown to be associated with increased risk of Ml/ischemic $\mathrm{HF}(8)$ and the toxic pollutants increase the risk of cardiopulmonary diseases(9).

During COVID-19 lockdown, the number of cases reported to ER and outpatient clinics for non-COVID infections, injuries, metabolic disorders, psychotic conditions and $\mathrm{Ml}$ have come down in the hospitals across the state of Tamil Nadu, India. It is clear from the Table I that the number of HF and ER attendance during no-lockdown period was almost consistent, whereas the total number of HF has increased with a decrease in ER attendance during lockdown. However, reports published across the globe have shown a reduction in the HF admissions(3-5).

Though the exact reasons for surge in the HF occurrence in our population remain unclear, we attribute this to the prevailing doctor centred practice, lack of doctor-patient communication (10) and underutilisation and reduced availability of healthcare technologies including telehealth and virtual consultation services. In addition, social deprivation/loneliness, COVID-19 related anxiety(11), unemployment and financial constraints contributing to poor compliance with medications; staying at home leading to non-adherence to diet and fluid intake causing weight gain/obesity(12); changing over to alternative therapies/drugs, consumption of prophylactic hydroxychloroquine to prevent COVID-19 infection(13), withdrawal/dose reduction of angiotensin converting enzyme inhibitors/angiotensin receptor blockade drugs due to fear of COVID-19 illness by some physicians/patients(14), non-adherence to dialysis schedule and delay in seeking medical attention due to fear of acquiring COVID-19(15). In addition to the above, underinvestment in public health system and social benefits in India might have also contributed(16).

Generally, HF is a chronic condition with the occurrence of acute decompensation due to many reasons including those stated above. Hence, there is a need for patient centred practice, enhancement of doctorpatient relationship, introduction of patient education and counselling along with re-engineering of health care service and delivery(15). The follow-up care has to be ensured for chronic conditions using telephone or virtual consultations(17). Further studies are warranted in the application of virtual 
technology including m-health and artificial intelligence in places with infrastructure limitations so as to improve the patient's compliance and long-term management of HF.

\section{Abbreviations}

Severe acute respiratory distress syndrome coronavirus 2019 (SARS CoV2, COVID-19)

Myocardial infarction (MI)

Heart failure (HF)

Emergency room (ER)

Ejection fraction (EF)

$\mathrm{EF} \geq 50 \%(\mathrm{HFpEF})$

$\mathrm{EF}<40 \%(\mathrm{HFrEF})$

Ischemic HF (IHF)

Non-ischemic HF (NIHF)

\section{Declarations}

Ethics approval - obtained

Ethical committee - Manian Medical Centre, Erode, India

Conflict of interest: Nil

Financial disclosures: Nil

Consent for publication: obtained from all authors

Funding: no funding obtained

Availability of data: already included in the manuscript

The patients included in this report have not been reported in any other submission.

\section{Contributor statement:}

RM - study design and protocol, arrangement for data collection, statistical analysis, manuscript drafting and revision including reference collection, manuscript submission 
SS - ethical board approval, data collection, statistical interpretation, manuscript revision

PT - Study design and protocol, statistical interpretation, manuscript revision

MJ - data analysis and statistical interpretation, manuscript review

NNJ - data collection, manuscript review

SA - data collection, manuscript review

VPC - data collection, manuscript review

\section{Acknowledgement:}

We would like to thank Professor Lakshmanan Jeyaseelan, Department of Biostatistics, Christian Medical College, Vellore 632002, India; for his valuable guidance for statistical work in this paper.

\section{STROBE Guidelines:}

It is included in the manuscript. Please refer page number 4 under the section 'Methods' in that paragraph 1.

\section{References}

1. The Lancet. India under COVID-19 lockdown. Lancet [Internet]. 2020 Apr;395(10233):1315. Available from: https://linkinghub.elsevier.com/retrieve/pii/S0140673620309387.

2. $10.1056 /$ NEJMc2009166

De Filippo O, D’Ascenzo F, Angelini F, Bocchino PP, Conrotto F, Saglietto A, et al. Reduced Rate of Hospital Admissions for ACS during Covid-19 Outbreak in Northern Italy. N Engl J Med [Internet]. 2020 Apr 28;NEJMc2009166. Available from: http://www.nejm.org/doi/10.1056/NEJMc2009166.

3. HALL ME, VADUGANATHAN M, KHAN MS, PAPADIMITRIOU L, LONG RC, HERNANDEZ GA, et al. Reductions in Heart Failure Hospitalizations During the COVID-19 Pandemic. J Card Fail. 2020.

4. $10.1002 /$ ejhf.1925

Bromage DI, Cannata A, Rind IA, Gregorio C, Piper S, Shah AM, et al. The impact of COVID-19 on heart failure hospitalization and management: report from a Heart Failure Unit in London during the peak of the pandemic. Eur J Heart Fail [Internet]. 2020 Jun;ejhf.1925. Available from: https://onlinelibrary.wiley.com/doi/abs/10.1002/ejhf.1925.

5. 10.1161/CIRCHEARTFAILURE.120.007274

Andersson C, Gerds T, Fosbøl E, Phelps M, Andersen J, Lamberts M, et al. Incidence of New-Onset and Worsening Heart Failure Before and After the COVID-19 Epidemic Lockdown in Denmark. Circ Hear Fail [Internet]. 2020 Jun;13(6). Available from:

https://www.ahajournals.org/doi/10.1161/CIRCHEARTFAILURE.120.007274. 
6. Pfeffer MA, Shah AM, Borlaug BA. Heart Failure with Preserved Ejection Fraction in Perspective. Circulation Research. 2019.

7. Meenakshisundaram Ramachandran S, Subramanian T, Ponniah M, Joy NN, Jena R, Vadivelu S, Ayyasamy VC. Status of Acute Myocardial Infarction in Southern India during COVID-19 Lockdown: A Multi-centric Study. Mayo Clin Proc Innov Qual Outcomes. 2020;(Accepepted for Publication).

8. Kuźma Ł, Pogorzelski S, Struniawski K, Dobrzycki S, Bachórzewska-Gajewska H. Evaluation of the influence of air pollution on the number of hospital admissions for acute coronary syndrome in elderly patients (BIA - ACS Registry). Polish Arch Intern Med [Internet]. 2019 Nov 19;130(1):38-46. Available from: https://www.mp.pl/paim/issue/article/15064.

9. 10.1186/1476-072X-9-41

Loughnan ME, Nicholls N, Tapper NJ. The effects of summer temperature, age and socioeconomic circumstance on Acute Myocardial Infarction admissions in Melbourne, Australia. Int J Health Geogr [Internet]. 2010;9(1):41. Available from: http://ijhealthgeographics.biomedcentral.com/articles/10.1186/1476-072X-9-41.

10. Kosunen E. Teaching a patient-centred approach and communication skills needs to be extended to clinical and postgraduate training: A challenge to general practice. Scandinavian Journal of Primary Health Care. 2008.

11. $10.1177 / 2047487318792696$

Valtorta NK, Kanaan M, Gilbody S, Hanratty B. Loneliness, social isolation and risk of cardiovascular disease in the English Longitudinal Study of Ageing. Eur J Prev Cardiol [Internet]. 2018 Sep 2;25(13):1387-96. Available from: http://journals.sagepub.com/doi/10.1177/2047487318792696.

12. Mamas M. COVID-19: “Lockdown 15” Weight Gain Metabolic Implications and Risks. Medscape [Internet]. Available from: https://www.medscape.com/viewarticle/929858\#vp_1.

13. Rathi S, Ish P, Kalantri A, Kalantri S. Hydroxychloroquine prophylaxis for COVID-19 contacts in India. Lancet Infect Dis [Internet]. 2020 Apr; Available from: https://linkinghub.elsevier.com/retrieve/pii/S1473309920303133.

14. Vaduganathan M, van Meijgaard J, Mehra MR, Joseph J, O’Donnell CJ, Warraich HJ. Prescription Fill Patterns for Commonly Used Drugs During the COVID-19 Pandemic in the United States. JAMA [Internet]. 2020 Jun 23;323(24):2524. Available from: https://jamanetwork.com/journals/jama/fullarticle/2766773.

15. Ardati AK, Lora AJM. Be Prepared. Circulation: Cardiovascular Quality and Outcomes; 2020.

16. Mahaveer Golechha. India Should Ramp Up Its Emergency Medicine and Critical Care Infrastructure to Combat COVID-19. Postgr Med J [Internet]. 2020;(postgradmedj-2020-138249). Available from: https://pubmed.ncbi.nlm.nih.gov/32561597/.

17. Gorodeski EZ, Goyal P, Cox ZL, Thibodeau JT, Reay RE, Rasmusson K, et al. Virtual Visits for Care of Patients with Heart Failure in the Era of COVID-19: A Statement from the Heart Failure Society of America. J Card Fail [Internet]. 2020 Jun;26(6):448-56. Available from:

https://linkinghub.elsevier.com/retrieve/pii/S1071916420303675. 


\section{Tables}

Table I: Data on Heart Failure and Emergency Room Attendance cases

\begin{tabular}{|lllllllll|}
\hline Period & $\begin{array}{l}\text { Ischemic } \\
\text { heart } \\
\text { failure }\end{array}$ & $\begin{array}{l}\text { Non- } \\
\text { ischemic } \\
\text { heart } \\
\text { failure }\end{array}$ & $\begin{array}{l}\text { Total } \\
\text { heart } \\
\text { failure }\end{array}$ & HFpEF & HFrEF & Male & Female & $\begin{array}{l}\text { Number } \\
\text { Of } \\
\text { emergency } \\
\text { room }\end{array}$ \\
attendance
\end{tabular}

Legend:HFpEF - HF with preserved ejection fraction, HFrEF: HF with reduced ejection fraction.

Table Il: Analysis of Heart Failure treated during Covid-19 Lockdownand No-lockdown Periods 


\begin{tabular}{|c|c|c|c|c|c|}
\hline Variables & P1 & P2 & $\begin{array}{l}\text { Proportion } \\
\text { Difference }\end{array}$ & 95\% C.I & $p$ value \\
\hline IHF (Apr 20 vs Feb 20) & 0.36 & 0.44 & -0.08 & $\begin{array}{l}-0.14 \\
-0.03\end{array}$ & 0.003 \\
\hline IHF (Apr 20 vs Apr 19) & 0.36 & 0.40 & -0.05 & $-0.1,0.01$ & 0.112 \\
\hline IHF (Apr 20 vs Apr 18) & 0.36 & 0.43 & -0.08 & $\begin{array}{l}-0.14 \\
-0.02\end{array}$ & 0.008 \\
\hline NIHF (Apr 20 vs Feb 20) & 0.64 & 0.56 & 0.08 & $0.03,0.14$ & 0.003 \\
\hline NIHF (Apr 20 vs Apr 19) & 0.64 & 0.60 & 0.05 & $-0.01,0.1$ & 0.112 \\
\hline NIHF (Apr 20 vs Apr 18) & 0.64 & 0.57 & 0.08 & $0.02,0.14$ & 0.008 \\
\hline HFpEF (Apr 20 vs Feb 20) & 0.57 & 0.56 & 0.001 & $-0.06,0.06$ & 1.000 \\
\hline HFpEF (Apr 20 vs Apr 19) & 0.57 & 0.55 & 0.01 & $-0.05,0.07$ & 0.703 \\
\hline HFpEF (Apr 20 vs Apr 18) & 0.57 & 0.57 & -0.01 & $-0.06,0.05$ & 0.892 \\
\hline HFrEF (Apr 20 vs Feb 20) & 0.43 & 0.44 & -0.001 & $-0.06,0.06$ & 1.000 \\
\hline HFrEF (Apr 20 vs Apr 19) & 0.43 & 0.45 & -0.01 & $-0.07,0.05$ & 0.703 \\
\hline HFrEF (Apr 20 vs Apr 18) & 0.43 & 0.43 & 0.01 & $-0.05,0.06$ & 0.892 \\
\hline Male (Apr 20 vs Feb 20) & 0.55 & 0.56 & -0.004 & $-0.06,0.05$ & 0.933 \\
\hline Male (Apr 20 vs Apr 19) & 0.55 & 0.57 & -0.02 & $-0.07,0.04$ & 0.635 \\
\hline Male (Apr 20 vs Apr 18) & 0.55 & 0.59 & -0.03 & $-0.09,0.02$ & 0.266 \\
\hline Female (Apr 20 vs Feb 20) & 0.45 & 0.44 & 0.004 & $-0.05,0.06$ & 0.933 \\
\hline Female (Apr 20 vs Apr 19) & 0.45 & 0.43 & 0.02 & $-0.04,0.07$ & 0.635 \\
\hline Female (Apr 20 vs Apr 18) & 0.45 & 0.41 & 0.03 & $-0.02,0.09$ & 0.266 \\
\hline $\begin{array}{l}\text { Total Heart Failure (Apr } 20 \text { vs Feb } \\
\text { 20) }\end{array}$ & 0.26 & 0.13 & 0.12 & $0.1,0.14$ & $<0.001$ \\
\hline $\begin{array}{l}\text { Total Heart Failure (Apr } 20 \text { vs Apr } \\
\text { 19) }\end{array}$ & 0.26 & 0.13 & 0.13 & $0.11,0.15$ & $<0.001$ \\
\hline $\begin{array}{l}\text { Total Heart Failure (Apr } 20 \text { vs Apr } \\
\text { 18) }\end{array}$ & 0.26 & 0.13 & 0.13 & $0.11,0.15$ & $<0.001$ \\
\hline
\end{tabular}

Legend:P1: proportion of cases treated during Covid-19 lockdown period; P2: proportion of cases treated in no-lockdown period;IHF: Ischemic Heart Failure; NIHF:Non-ischemic Heart Failure; HFrEF-heart failure (HF) with reduced ejection fraction, HFpEF: HF with preserved ejection fraction ,vs - Versus, Apr - April, Feb. - February, C.I: confidence interval, 95\% confidence interval for the difference in the proportion, BOLD: significant $P$-value. 